\title{
Rate of removal of grass from mixed pastures by cattle, sheep and goat grazing
}

\author{
K. BETTERIDGE, R.H. FLETCHER, Y. LIU', D.A. COSTALL and B.P. DEVANTIER \\ AgResearch Grasslands, Private Bag 11008, Palmerston North \\ 'National Grassland Research Institute, Huhehot, Inner Mongolia. P.R.C.
}

\section{Abstract}

A study was undertaken to compare the reduction in the length of grass tillers in two temperate mixed pastures grazed by cattle, sheep and goats alone, in spring. One hundred identified tillers in each of 24 plots (2 reps per pasture type) were measured daily during grazing periods of 3 (GD3) or 6 (GD6) days and disappearance rate of grass was determined. Initial pasture mass was similar for all treatments (mean $=3500 \mathrm{~kg}$ dry matter/ha). Paddock area for GD6 was twice that for GD3 so that the nominal daily DM allowance $/ \mathrm{kg}$ liveweight $^{0.9}$ was the same for each animal group at the start of the trial. Cattle ate taller than average tillers while sheep and goats ate tillers of a length closer to that of the mean tiller length $(\mathrm{P}<0.01)$. Also, cattle removed a greater proportion $(52 \%)$ of the tiller length available each time it was grazed than sheep and goats $(43-46 \%)(\mathrm{P}<0.01)$. Length of tiller removed at grazing was highly correlated $\left(\mathrm{r}^{2}=0.99\right)$ with length of the tiller prior to grazing, for each animal species, over the range 60-340 $\mathrm{mm}$ tiller length. Animals on the GD3 ${ }^{-}$treatment removed more of the tiller $(50 \%)$ per grazing than on GD6 treatments $(46 \%)(\mathrm{P}<0.05)$, but the average number of grazings per tiller on GD3 and GD6 treatments was similar $(0.55$ times/day $)$. The length of tillers at the end of grazing was shorter for cattle $(68 \mathrm{~mm})$ than goats $(106 \mathrm{~mm})$ or sheep $(123$ $\mathrm{mm})(\mathrm{P}<0.05)$, and was shorter for GD6 $(87 \mathrm{~mm})$ than GD3 $(111 \mathrm{~mm})(\mathrm{P}<0.05)$. Pasture type did not affect grazing behaviour.

K eywords: cattle, foraging strategy, goats, grass tillers, sheep

\section{Introduction}

Growing animals to "specification" for particular markets is a direction being taken by many progressive farmers, To do this they require precise knowledge of how to feed stock to meet the target. Decision support models are a means to assist farmers achieve this objective more efficiently but these models can be built only from results of detailed studies of animal behaviour and performance. The work reported here was designed to determine whether cattle, sheep and goats, when offered similar allowances of two different pasture types, gave a similar utilisation of the grass tillers, using 2 management stategies. Pasture was budgeted to feed animals for 3 or 6 days of continuous grazing, on the basis of a common daily feed allowance per $\mathrm{kg} \mathrm{LW} \mathbf{L W}^{0.9}$. This liveweight scaling factor has been shown to allow comparison between animal species (Ternouth et al., cited Minson \& Whiteman 1989).

$M$ aterials and methods

\section{Design}

The trial used a split-plot design with 2 within-blockreplicates of 2 pasture types (PT) (main plots). Three animal types (A) grazed each of 2 grazing duration (GD) treatments (subplots, later referred to as grazing densities), using 24 plots ranging in size from $38-540$ $\mathrm{m}^{2}$. The two replicates within PT (paddocks) each contained 6 plots (see Figure 1). Animal (A) treatments were applied using two subgroups of each animal type The A subgroup grazing one GD effect in rep 1, grazed the other GD effect ${ }^{-}$in rep ${ }^{-2}$, within' ${ }^{-}$each-PT-, $^{-}$sos- to $^{-}$ remove sub-group variation.

Figure 1 Diagrammatic trial layout for reps within a pasture type. Cattle, sheep and goat animal treatments are shown with grazing durations of 3 days $\left(\mathrm{GD}_{3}\right)$ and 6 days $\left(\mathrm{GD}_{\boldsymbol{k}}\right)$. Animal subgroups (a) and (b) are also indicated."

\begin{tabular}{|c|c|c|c|c|c|c|c|}
\hline \multicolumn{8}{|c|}{ CATTLE PASTURE } \\
\hline $\begin{array}{c}\text { Cattle } \\
\text { (a) } \\
\mathrm{GO}_{6}\end{array}$ & $\begin{array}{l}\text { Cattle } \\
\text { (b) } \\
\mathrm{GD}_{3}\end{array}$ & $\begin{array}{l}\begin{array}{l}\text { Goats } \\
\text { (b) } \\
\mathrm{GD}_{3}\end{array} \\
\text { Sheep } \\
\text { (b) } \\
\mathrm{GD}_{6}\end{array}$ & $\begin{array}{l}\text { Sheep } \\
\text { (a) } \\
\mathrm{GD}_{3} \\
\text { Goats } \\
\text { (a) } \\
\mathrm{GD}_{6}\end{array}$ & $\begin{array}{l}\text { Cattle } \\
\text { (a) } \\
\mathrm{GD}_{3}\end{array}$ & $\begin{array}{l}\text { Goats } \\
\text { (a) } \\
\mathrm{GD}_{6} \\
\\
\text { Sheep } \\
\text { (a) } \\
\mathrm{GD}_{6}\end{array}$ & 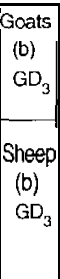 & $\begin{array}{c}\text { Cattle } \\
\text { (b) } \\
G \quad D_{\hat{6}}\end{array}$ \\
\hline
\end{tabular}

\section{Pastures (PT)}

Two pasture types were used: a 2-year-old cattle-grazed sward of sweet vernal (Anthoxanthum odoratum) 
(31\%). Yorkshire fog (Holcus lanatus) (21\%), Grasslands Roa tall fescue (Festuca arundinacea Schreb.) (18\%) and white clover (Trifolium repens L.) $(14 \%)$ with a low tiller density $\left(6400 / \mathrm{m}^{2}\right)$ - PTl; and a sheep-grazed sward of browntop (Agrotis tenuis Sibth.) (29\%), sweet vernal $(21 \%)$ and'white clover (24\%) with a high tiller density $\left(26400 / \mathbf{m}^{2}\right)$ - PT2. A majority of tagged tillers (61\%) had partially or fully developed seed-heads at grazing, especially in the third and fourth weeks.

Pastures were prepared in mid-spring by hardgrazing with cattle (PT1) or sheep (PT2). Urea was applied at $30 \mathrm{~kg} \mathrm{~N} /$ ha four weeks before grazing of each paddock. Two weeks before grazing, pastures were mown $(75 \mathrm{~mm})$ to minimise effects of dung and urine, and clippings were removed. Grazing treatments commenced on 9 November 1992 on PT1, rep 1, and proceeded in consecutive weeks to the other three paddocks (Table 1).

Animals (A)

Four mature Simmental cows $(480 \mathrm{~kg})$, six 2 tooth Romney ewes (42 kg) and eight 2 tooth Angora goats (21 kg) (4 male, 4 female) were weighed and allocated to the two A subgroups. Animal subgroups $(\mathrm{a}, \mathrm{b})$ were switched between GD treatments in moving from rep 1 to rep 2 within each PT.

Grazing density (GD)

Paddock sizes were varied to provide a nominal 15.8, 1.18 and $0.9 \mathrm{~kg} \mathrm{DM} /$ animal/day above ground level at the start of a grazing period, for cattle, sheep and goats respectively. This was based on an assumed mass of $3500 \mathrm{~kg} \mathrm{DM} / \mathrm{ha}$ within each paddock and a constant stocking density of 0.94 and $1.85 \mathrm{~kg} \mathrm{LW} 0.9 / \mathrm{m}^{2}$ for 6 and 3 days (GD6 \& GD3) respectively. As pasture mass was not $3500 \mathrm{~kg} \mathrm{DM} / \mathrm{ha}$ at the start of grazing of each paddock, true allowance varied between paddocks, but not between $\mathrm{A}$ and GD treatments.

\section{Measurements}

\section{Extended tiller height (ETH)}

In each of the 24 paddocks each of 100 randomly selected grass tillers was tagged using a coloured paper clip held to the ground with a $75 \mathrm{~mm}$ flat-head nail. ETH, measured daily, was the longest plant part, and LGP the shortest grazed plant part, held vertically above ground level (see Figure 2). Grazed extended tiller height $\left(\mathbf{E T H}_{\mathrm{G}}\right)$ was the length of a tiller at the start of the day, which was recorded as being at least $5 \mathrm{~mm}$ shorter $24 \mathrm{~h}$ later. On that day other tillers were recorded as ungrazed (ETH,).
Table 1 Mean extended tiller height (ETH) and pasture mass $( \pm \mathrm{SE})$ prior to grazing of each rep within-pasture type.

\begin{tabular}{ccccc}
\hline PT & $\begin{array}{c}\text { Within-PT } \\
\text { rep }\end{array}$ & Date & $\begin{array}{c}\text { Inititial ETH } \\
(\mathbf{m m})\end{array}$ & $\begin{array}{c}\text { Inititial pasture } \\
\text { mass }(\mathrm{kg} \text { DM/ha) }\end{array}$ \\
\hline 1 & 1 & 9 Nov & $175( \pm 2.5)$ & $2506( \pm 266)$ \\
& 2 & 30 Nov & $314( \pm 4.2)$ & $4050( \pm 195)$ \\
2 & 1 & 16 Nov & $\mathbf{2 4 4 ( \pm 3 . 1 )}$ & $3150( \pm 451)$ \\
& 2 & 23 Nov & $215( \pm 3.5)$ & $4100( \pm 783)$ \\
\hline
\end{tabular}

The length of tiller removed during the preceding $24 \mathrm{~h}$ was determined as $\mathbf{E T H}_{\mathrm{Gi}-\mathrm{I}} \cdot \mathbf{L G P}_{\mathbf{i}}\left(=\mathbf{R}_{\mathbf{i}}\right)$ (Figure 2). Daily mean $\mathbf{R}_{\mathbf{i}}\left(\sum \mathrm{R}_{\mathbf{i}} / \mathbf{n}_{\mathrm{Gi}-1}\right)$ and mean $\mathbf{E T H} \mathrm{Gi}_{\mathrm{G}}$ 1 values within plots were used in a regression model to determine the rate of reduction of tiller length. The frequency over the trial period with which each tiller was grazed, and the proportion of all tillers grazed per day was determined.

Pasture mass (kg DM/ha) was determined daily from washed samples taken from four $1 \mathrm{~m} \times 75 \mathrm{~mm}$ strips to ground level.

Figure 2 Description of plant measurements - extended tiller height $(\mathrm{ETH}$, ,); lowest grazed part (LGP); length of tiller removed(R) being $\left(\mathbf{E T H}_{\mathrm{Gi-1}}-\mathrm{LGP}_{\mathrm{i}}\right)$.

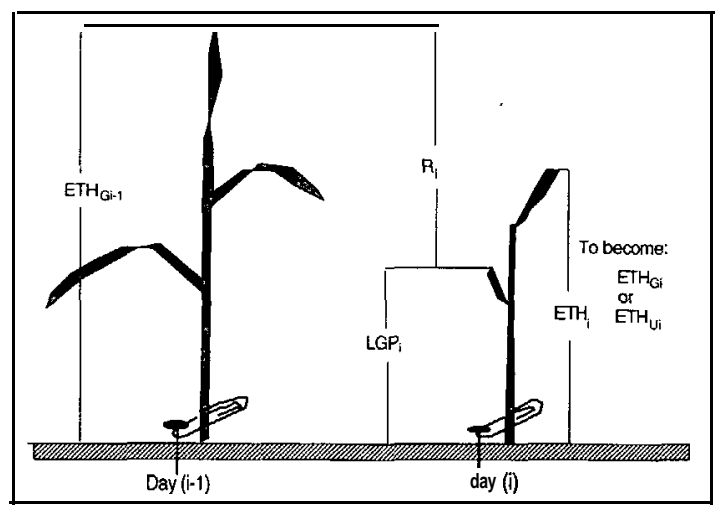

\section{Results}

Tiller height (ETH) and pasture mass

Mean ETH of tagged tillers $(237 \mathrm{~mm})$ and mean pasture mass $(3450 \mathrm{~kg} \mathrm{DM} / \mathrm{ha})$ at the start of the trial was similar between PT treatments (Table 1) and subplot treatments ( $\mathrm{P}>0.05$ ). Rep 2 paddocks had more mass then Rep 1 paddocks within PT treatments, as pastures became reproductive. Mean ETH and mean length of tillers either grazed $\left(\mathrm{ETH}_{\mathrm{G}}\right)$ or ungrazed $(\mathrm{ETH}$,$) during the following 24 \mathrm{~h}$ are shown in Figure 3 . Only $5 \%$ and $7 \%$ of tillers were "lost" from GD3 and GD6 treatments respectively. 


\section{Selection of tillers to be grazed}

Initial length of tillers which were grazed during a day $\left(\mathbf{E T H}_{\mathrm{G}}\right)$, regressed upon the length of those not grazed (ETH,) gave pooled equations of:

$$
\begin{aligned}
& Y_{c}=54.4(k 6.1)+0.83( \pm 0.04) X \\
& Y_{g}=39.9( \pm 8.8)+0.84( \pm 0.05) X \\
& Y_{s}=50.1( \pm 10.4)+0.81( \pm 0.05) X
\end{aligned}
$$

where $\mathbf{Y}_{\mathbf{c}}, \mathbf{Y}_{\mathbf{g}}$ and $\mathbf{Y}_{\mathbf{s}}(\mathrm{mm})=\mathbf{E T H}_{\mathbf{G}}$ and $\mathrm{X}(\mathrm{mm})=$ $\mathrm{ETH}$, during a $24 \mathrm{hr}$ period, for cattle, goats and sheep respectively. These show cattle ate longer tillers ("a" in $\mathrm{Y}=\mathrm{a}+\mathrm{bX}$ ) than goats $(\mathrm{P}<0.01)$. Cattle, and to a lesser extent sheep and goats, increasingly selected the longer tillers, as mean ETH decreased (Figure 3).

Mean final ETH of all GD3 tillers was shorter for cattle and goats (58 and 87\%) than for sheep $(100 \% ; \mathrm{P}<0.05)$ and relative mean final ETH in GD6 pastures was 54, 85 and $100 \%(\mathrm{P}<0.05)$ for cattle, goats and sheep, respectively (Figure 3). At the end of grazing, GD3 tillers $(111 \mathrm{~mm})$ were longer than GD6 tillers $(87 \mathrm{~mm} ; \mathrm{P}<0.05)$. A higher proportion of tagged tillers were grazed on each of the first three days in GD3 (0.63) than in GD6 (0.48) treatments $(P<0.001$; Figure 3$)$ and cattle grazed a higher proportion of tillers per day $(0.60)$ than sheep $(0.55 ; \mathrm{P}<0.01)$. On a daily basis, each tiller was grazed 0.55 times irrespective of GD effect $(\mathrm{P}<0.05)$. No more than $69 \%$ of all tagged tillers were grazed on any one day.

\section{Rate of reduction-of-tiller-length}

Mean length of tiller removed (mR; pooled for GD and PT) during $24 \mathrm{~h}$ for each tiller grazed was regressed on the respective mean ETH, (Figure 4). Each intercept was not significantly different from zero ( $>>0.05$ ) so was fitted through the origin. The slope $(0.52)$ for cattle was greater than for goats $(0.45)$ and sheep (0.44) $(\mathrm{P}<0.001)$, indicating a greater rate of-reduction of-tiller- length; or "bite depth" per grazing of the tiller, for cattle. Cattle and sheep on GD3 had greater "bite depths" than on GD6 treatments $(\mathrm{P}<0.05)$ but there was no difference between GD3 and GD6 for goats $(\mathrm{P}>0.05)$. Overall, animals on GD3 removed $50 \%$ (viz. slope $=0.50$ ) and on GD6 46\% (P<0.001) of the tiller when a tiller was grazed.
Figure 3 Mean tiller length of 100 tagged tillers at the start of a $24 \mathrm{~h}$ period and mean height of tillers grazed $\left(\mathrm{ETH}_{G} ; 0\right)$ and ungrazed $(\mathrm{ETH}, ; \star)$ ) during the following $24 \mathrm{~h}$ for 3 and 6 days of grazing.

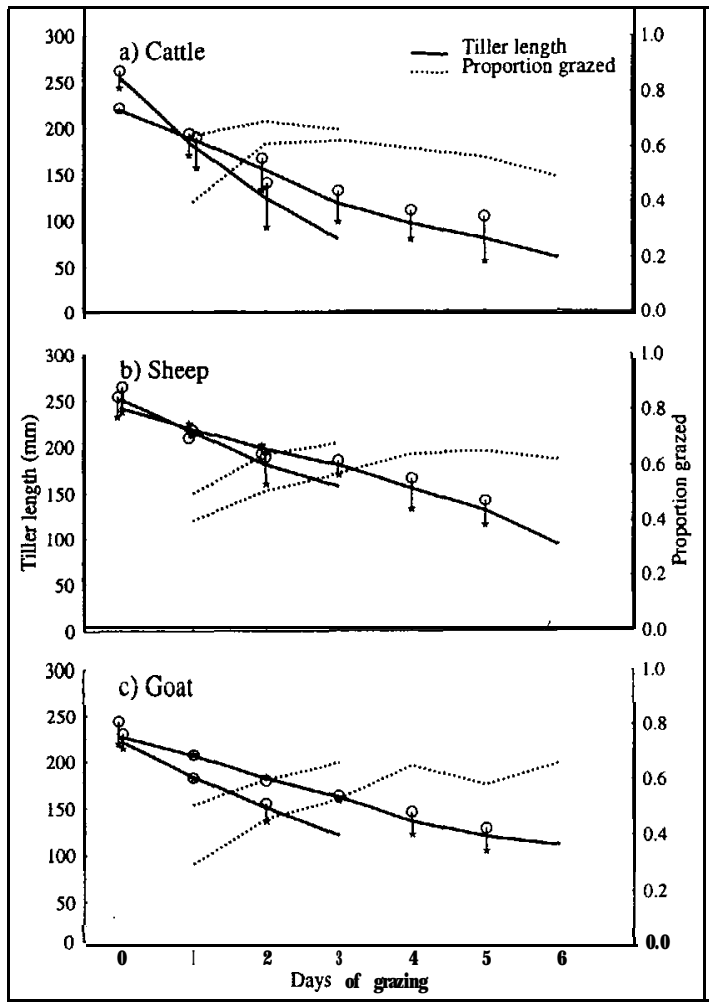

Figure 4 Fitted regression lines ( \pm SE of slope) of mean length of tiller removed during Day, (AvR,) versus mean length of those same tillers measured on-Day ${ }_{\mathrm{i}-1}\left(\mathrm{ETH}_{\mathrm{Gi-1}}\right)$-for-cattle,sheep-and-goats.-Plotted-points-(n=36) animal species) are mean lengths from GD within PT treatments measured at the end of each day. Slope of regression represents rate of reduction of the length of grazed tillers.

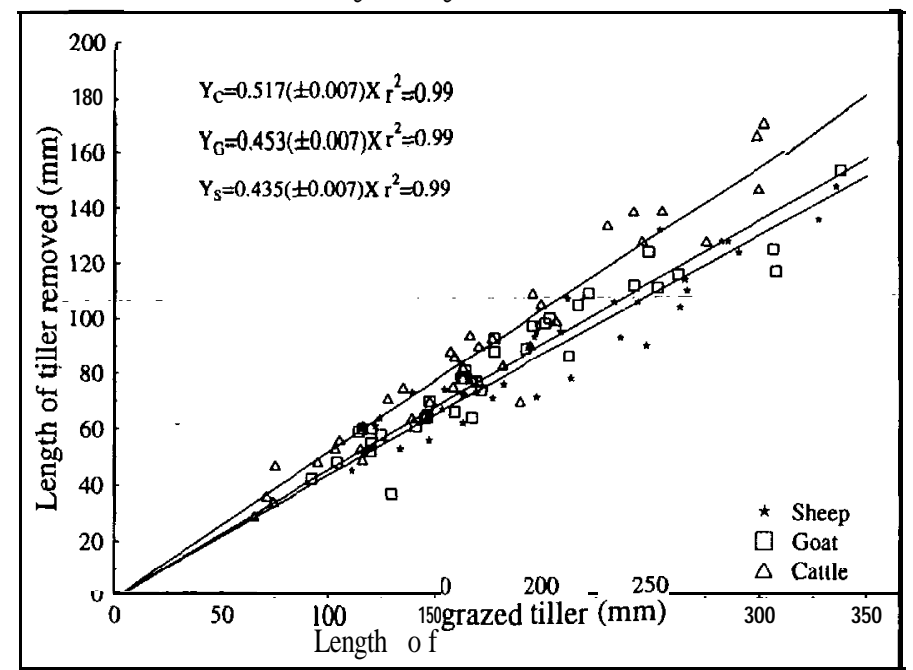




\section{Discussion}

\section{Tiller length}

There was a constant rate of reduction of tiller length (in the mean ETH range 340 down to $60 \mathrm{~mm}$ ) in relation to ETH of the tiller each time it was grazed. This constant reduction rate of $52 \%$ for our cows was similar to that reported by Wade (1991) using dairy cows (46\%) which grazed vegetative tillers within a similar ETH range. The sheep and goats removed 45 and $44 \%$ of the ETH respectively, but no comparable data have been found in the literature.

The length of tiller removed during a day may not equate to "bite depth", as defined in feeding trials, because tillers in this study were generally not erect after the first day and because it was not established how many times within a day a tiller was defoliated. It is, however, comparable with the "depth of grazing" which Wade (1991) used to describe the dynamics of grazing by dairy cows in a S-day paddock system.

Our results confirm that ETH, even in a trampled pasture, is a major determinant of length or depth of grazing. This is surprising as the strong positive relationship between bite depth and pasture height, established in untrodden turves (Mursan et al. 1989; Betteridge et al. 1991; Laca et al. 1992), is now shown to be just as strong as the relationship between depth of grazing and ETH in the long trampled pastures (after Day 1) in this trial. Presumably, in shorter vegetative pastures, ETH and pasture height will be similar, because leaves and pseudostems are likely to remain upright.

Herbage DM allowance at the start of the trial was calculated to provide each animal with a similar daily mass per $\mathrm{kg} \mathrm{LW} \mathbf{L W}^{0.9}$ during each day it was on the trial. However, final ETH of GD3 tillers was longer than for GD6 tillers, indicating different grazing behaviour. But, as the rate of decline in ETH on the GD6 treatment (46\% of tiller) was similar to that of the GD3 treatment ( $50 \%$ of tiller), and because there were only small differences in the proportion of tagged tillers being grazed each day (GD3 0.63 cf. GD6 0.48) (Figure 3), it is not surprising that GD6 tillers (and pastures) were shorter than GD3 tillers at the end of grazing, since the grazing period was twice as long.

The scaling of live weight, using the factor $\mathbf{L W}^{\mathbf{0 . 9}}$, to estimate daily allowance, was done to remove differences between animal species. However, the shorter residual tiller length in cattle, than in sheep and goat pastures at the end of grazing, indicated that cattle had a greater mean daily intake. This resulted from cattle removing more of the tiller per bite and having a higher frequency of defoliation of each tagged tiller during the grazing period, compared to sheep and goats. Collins \& Nicol (1986) similarly showed, in a "put and take" grazing experiment, that the apparent daily intake of sheep and goats decreased more quickly than for cattle grazing similar pastures. Whereas they found that the intake difference between animal species was less when herbage mass was removed quickly (cf. GD3) rather than slowly (cf. GD6), our result showed the relative ETH of tillers left by cattle, goats and sheep was the same for GD3 and GD6 treatments. In a study with lambs grazing luceme, White \& Cosgrove (1990) showed a lower residual ETH following a 12-day compared with a 3 . day grazing duration, despite animals being offered an equivalent daily herbage allowance at the start of the trial. They attributed this to a behavioural difference independent of luceme height, and suggested that average daily intakes may be higher at a lower grazing density because the animals would have less competition when grazing pastures with a high pasture mass on which intake would not have been restricted.

These results indicate that cattle will achieve higher utilisation and a greater intake than sheep or goats on a similar pasture, over the same time period. They also indicate that at a common and high mean daily DM allowance, a longer grazing duration (at least up to 6 days) in a large paddock will result in higher pasture utilisation than a shorter duration in a small paddock, at least when soil pugging is not an issue.

To remove a greater length of tiller per day than sheep or goats, we suggest cattle "selected" the longer of the tillers available to them, from the second day onwards, when mean ETH, $<320 \mathrm{~mm}$. By contrast sheep and goats became selective for the longer-thanaverage tillers only when average ETH was $<270 \mathrm{~mm}$ for goats and $<245 \mathrm{~mm}$ for sheep. These were determined as the points below which the graphs of $\mathrm{ETH},=\mathrm{ETH}$, (ie. no selection), and ETH, = $\mathrm{a}+\mathrm{b}$ ETH, for cattle, sheep and goats intersected. An explanation for this phenomenon may be that because the length of tiller removed by sheep and goats was less than that of the cattle, the differential in length of tillers on offer was less, and so the potential to select longer tillers was also less. Alternative hypotheses are: 1) that "selection" is a reflection of behavioural differences between species, with sheep and goats having an ability to select higher quality diets than cattle, through taking smaller bites; or 2) animals were not selecting long tillers in preference to short tillers, but only eating those which were most readily accessible to them. For cattle, these would have been those which were longest, while for sheep and goats, with their smaller mouths, tillers within different horizontal strata may have been equally accessible. Our data cannot differentiate between animal pre- 
ference and plant accessibility and so "selection" has been used to describe the combination of these two effects.

The results of this, and any similar trials, will reflect the stock unit equivalence scaling factor chosen to equate different species and different liveweights of animals within species. The choice of the correct scaling factor to use is difficult as the literature gives no clear guidance.

\section{Pasture types}

Pastures were typical for late spring with many tillers having reached early seed-head development by grazing time. Although there was a large difference in tiller density and botanical composition between pasture types, this had no measurable impact on how cattle, sheep and goats utilised the tagged grass tillers. This was despite PT1 pastures containing a high content of tall fescue and Yorkshire fog, (with coarse leaves and stems), while PT2 pastures were predominantly fineleaved browntop and sweet vernal. The large difference in legume content between PT1 and PT2 pastures apparently had no effect on how the grass tillers were eaten, as there was no significant difference between the two pastures in any measured variable.

\section{Conclusion}

It is concluded that cattle, sheep and goats each removed a constant but different proportion of a grass's tiller length within a wide range of tiller length available, and that cattle removed more per bite by eating the longer of the tillers on offer. Cattle also tended to graze a greater proportion of the plot each day, thereby resulting in shorter residual ETH than either sheep or goats. Goats were more selective for tiller length than sheep; removed a similar length of tiller with each bite as sheep; but left a shorter residual ETH than sheep because they grazed a larger proportion of the paddock each day. Although utilisation was higher at a low than at a high stock density, at any given stocking rate, high daily intakes, for high animal performance, will be achieved only by offering long pastures which enable large bite sizes. This trial shows that the residual pasture height at which cattle, sheep and goats must be removed, if they are to achieve the same relative performance, will differ for each animal species.

These results relate only to utilisation of long spring pastures and different relationships could result when animals graze vegetative pastures at other times of the year. Further, interaction between animal species grazing together was not measured. Hodgson et al. (1985) have indicated that sheep and cattle grazing together on pasture of $4.5 \mathrm{~cm}$ will have greater intakes than when grazing alone, but will have similar intakes on $3.0 \mathrm{~cm}$ pastures. Clearly, similar studies to ours, with mixed-species grazing, are needed to develop a robust, comprehensive model for grazing livestock.

\section{ACKNOWLEDGEMENTS}

We acknowledge Mr J. Davis and Ms K.L. Betteridge for technical assistance, $\mathrm{Mr} \mathrm{C}$. Hutchings for kindly providing the Simmental cows and Mrs C. Fletcher for providing the goats.

\section{REFERENCES}

Betteridge, K.; Shigeru Shioya; Kazuhiko Ochiai. 1991. Bite size characteristics of Holstein and Japanese Black steers grazing ryegrass-dominant pasture of different heights in boxes. Bull. National Grassland Research Institute (Japan) No 45: 73-82.

Collins, H.A.; Nicol, A.M. 1986. The consequence for feed dry matter intake of grazing sheep; cattle and goats to the same residual herbage mass. Proceedings of the New Zealand Society of Animal Production 46: 125-128.

Hodgson, J.; Arosteguy, J.C.; Forbes, T.D.A. 1985. Mixed grazing by sheep and cattle: effects on herbage production and utilisation. Proceedings of the 15th International Grassland Congress: 63-67.

Laca, E.A.; Ungar, E.D.; Seligman, N.; Demment, M.W. 1992. Effect of sward height and bulk density on bite dimensions of cattle grazing homogenous swards. Grass andforage science 47: 91-102.

Minson, D.J.; Whiteman, P.C. 1989. A standard livestock unit (SLU) for defining stocking rate in grazmg studies. Proceedings of the 16th International Grassland Congress: 1117- 1118.

Mursan, A.; Hughes, T.P.; Nicol, A.M.; Sugiura, T. 1989. The influence of sward height on the mechanics of grazing in steers and bulls. Proceedings of the New Zealand Society of Animal Production 49: 233$2 \quad 3 \quad 6$.

Wade, M.H. 1991. Factors affecting the availability of vegetative Lolium perenne to grazing dairy cows with special reference to sward characteristics; stocking rate and grazing method. PhD Thesis; L'Universite de Rennes; France.

White, J.G.H.; Cosgrove, G.P. 1990. Lucerne grazing management. 2. Effect of grazing duration on defoliation patterns by ewes. New Zealand journal of agricultural research 33: 621-625. 